\title{
KOADAPTASI PETANI DALAM PENGELOLAAN EKOSISTEM PERTANIAN PADA BUDIDAYA UBI KAYU DI DESA RANCAMANGGUNG KABUPATEN SUBANG (Farmers Coadaptation in Agroecosystem Management of Cassava Cultivation in Rancamanggung Village - Subang District)
}

\author{
Carolina* dan Fithria Novianti \\ Pusat Pengembangan Teknologi Tepat Guna, Lembaga Ilmu Pengetahuan Indonesia, \\ Jalan KS Tubun No. 5 - Subang. \\ *Penulis korespondensi. Tel: 0260-412878. Email: carolina.4q@ gmail.com.
}

Diterima: 12 Januari 2016

\begin{abstract}
Abstrak
Ubi kayu (Manihot esculenta) menjadi tanaman pokok sumber penghasilan bagi sebagian besar masyarakat petani di Desa Rancamanggung Kabupaten Subang selama tiga dekade. Fenomena tersebut menunjukkan bahwa mitos ubi kayu sebagai tanaman boros nutrisi dapat dipatahkan. Berdasarkan hal itu, dilakukan sebuah studi kasus yang bertujuan untuk mengenali inovasi pengelolaan ekosistem pertanian ubi kayu yang diterapkan oleh masyarakat petani di desa tersebut. Fokus diarahkan pada petani kecil pengelola lahan kurang dari $2000 \mathrm{~m}^{2}$. Secara umum petani kecil ditengarai sebagai komunnitas yang lebih rentan terhadap terhadap tekanan ekonomi yang kerap ditunjukkan melalui ekploitasi lingkungan berlebihan. Wawancara mendalam dan observasi langsung dilakukan untuk menggali fenomena lapangan. Dapat disimpulkan bahwa petani kecil di Desa Rancamanggung telah menunjukkan kemampuannya dalam mendayagunakan potensi lokal dengan baik. Penyesuaian terhadap dinamika ekosistem pertanian,Hal ini dibuktikan dengan kemampuan memenuhi permintaan pasar terhadap ubi kayu, yang cenderung meningkat. Di dalam keterbatasan sumber daya yang dikelola, pemenuhan permintaan pasar tersebut dipenuhi dengan melakukan inovasi pengelolaan ekosistem pertaniannya sehingga jumlah dan mutu hasil panen tetap dapat terjaga dalam jangka waktu panjang.
\end{abstract}

Kata kunci: ekosistem pertanian, inovasi, Manihot esculenta, petani kecil, ubi kayu.

\begin{abstract}
Cassava (Manihot esculenta) has been the main income generating crop for most farmers in Rancamanggung Village of Subang District during the last three decades. The phenomenon is breaking the myth about cassava as nutrient removal crop. Based on the observed fact, a case study was conducted to gain thorough understanding of the agroecosystem management performed by cassava farmers in the area. Focus was directed towards smallholders performance who manage less than $2000 \mathrm{~m}^{2}$ area of agricultural land. It is a common belief that smallholders are more prone to economic pressure leading to excessive environmental exploitation. Indepth interview and direct observation were conducted to explore field phenomenon. However, it is found that the smallholder farmers in Rancamanggung Village show their capability to reasonably optimize local resources. Adaptation to the dynamics of agroecosystem was indicated by their ability to fulfill the increasing market demand. Despite resources limitation, the smallhoder farmers continue to perform by managing their agroecosystem without any sign of productivity nor quality declination in a long period of time.
\end{abstract}

Keywords: agroecosystem, cassava, innovation, Manihot esculenta, smallholders.

\section{PENDAHULUAN}

Ubi kayu (Manihot esculenta Linn) merupakan tanaman pangan penting di Indonesia yang dibudidayakan untuk memenuhi kebutuhan pangan, pakan dan bahan baku untuk berbagai industri. Produksi lahan pertanian penghasil ubi kayu cenderung menunjukkan peningkatan dari tahun ke tahun. Hal ini karena pemerintah mencanangkan strategi intensifikasi diantaranya melalui penanaman bibit unggul, serta penggunaan pupuk dan pestisida sebagai upaya meningkatkan produktivitas. Keberhasilan ditunjukkan melalui peningkatan produktivitas lahan, yang semula adalah 202,17 kuintal/ha di tahun 2010, menjadi 229,91 kuintal/ha pada tahun 2014 (Anonim, 2014).

Upaya intensifikasi dalam kurun waktu panjang seringkali menimbulkan dampak negatif bilamana tidak dikelola dengan baik. Banyak kasus penurunan mutu lingkungan terjadi, baik dalam bentuk menurunnya kandungan nutrisi dalam tanah atau juga ledakan populasi hama tanaman yang mengganggu tidak hanya produktivitas akan tetapi juga keberlanjutan (Ruysschaert dkk., 2007; Mwango dkk., 2014). Akan halnya ubi kayu, Ruysschaert dkk. (2007) dan Howeler (2014) mengemukakan melalui kasus yang ditemui di berbagai negara bahwa ubi jayu tergolong tanaman 
yang memboroskan nutrisi tanah. Oleh karena itu diperlukan perhatian dan upaya khusus bilamana dijadikan tanaman pokok di suatu hamparan dalam jangka waktu panjang, Kasus yang dialami Thailand menjadi pelajaran berharga bagi Indonesia, degradasi mutu lingkungan yang cenderung tidak terbalikan terjadi sebagai akibat dari penanaman ubi kayu secara intensif (Tongchure dan Hoang, 2013; Howeler, 2014). Oleh karena itu, mengetahui strategi terbaik dalam mengelola lahan pertanian untuk budidaya ubi kayu menjadi informasi signifikan. Hal ini mengingat peran strategisnya sebagai komoditas ketahanan pangan, yang dapat menjadi sumber penghasilan bagi petani, sehingga dalam budidayanya memerlukan input sarana produksi dan tenaga kerja memadai layaknya komoditas komersial lainnya (Fermont dkk., 2010).

Berkaitan dengan hal itu maka, fenomena yang ditemukan di Desa Rancamanggung, Kecamatan Tanjungsiang, Kabupaten Subang adalah fakta penting. Kenyataan bahwa masyarakat petani di desa tersebut telah memanfaatkan lahan pertaniannya selama tiga dekade terus menerus untuk budidaya ubi kayu adanya penurunan produktivitas, adalah data yang layak dikaji. Sehubungan dengan hal itu, penelitian ini dilakukan dengan tujuan untuk mengenali strategi pengelolaan ekosistem pertanian ubi kayu yang dilakukan oleh petani di Desa Rancamanggung. Diharapkan akan diperoleh informasi bermanfaat bagi terbangunnya suatu ide penanganan lahan pertanian budi daya ubi kayu yang bekelanjutan.

\section{METODE PENELITIAN}

\section{Waktu dan Lokasi}

Penelitian ini dilakukan pada periode Januari Juni 2013 di Desa Rancamanggung Kecamatan Tanjungsiang, Kabupaten Subang, Provinsi Jawa Barat. Wilayah Desa Rancamanggung dipilih sebagai lokasi studi karena terkenal sebagai penghasil ubi kayu berkualitas bagus, khususnya sebagai bahan baku olahan pangan. Kecamatan yang terletak di sisi tenggara Kabupaten Subang ini berbatasan langsung dengan Kabupaten Sumedang yakni Desa Baregbeg Kecamatan Tannjungmedar di sisi timur, dan Desa Jingkang Kecamatan Tanjungmedar di sisi utara. Sementara itu, batas selatan adalah Desa Sindanglaya dan di sisi barat adalah Desa Gandasoli yang keduanya termasuk Kecamatan Tanjungsiang. Sebagian besar penduduk Desa Rancamanggung merupakan petani pembudidaya padi dan ubi kayu. Dibandingkan dengan 10 desa lainnya di Kecamatan Tanjungsiang, proporsi penduduk desa Rancamanggung yang membudidayakan ubi kayu adalah yang terbesar.

\section{Prosedur dan Analisis Data}

Penelitian dilakukan dengan menggunakan studi kasus sebagai pendekatan dalam memperoleh data dan informasi. Pendekatan ini dipilih untuk memahami fenomena koadaptasi petani dengan lingkungan pertaniannya melalui strategi pengelolaan agroekosistem budidaya ubi kayu. Kasus ini memenuhi kriteria yang disarikan oleh Yin

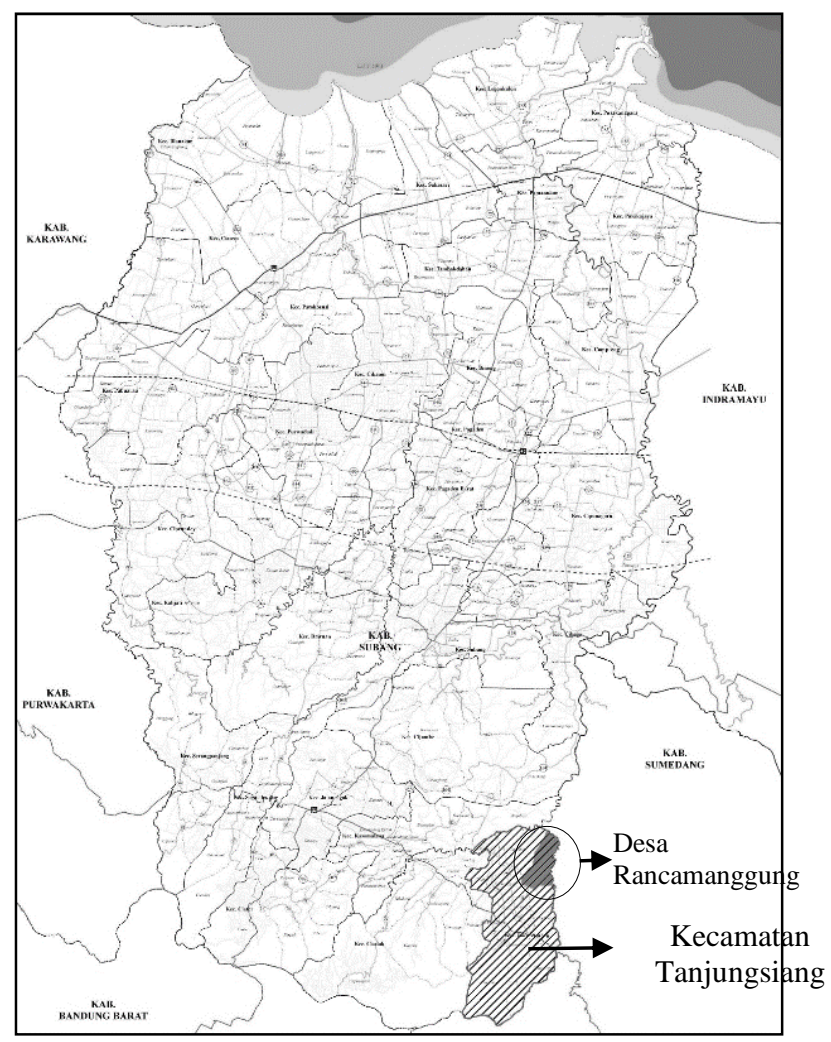

Kecamatan

Tanjungsiang

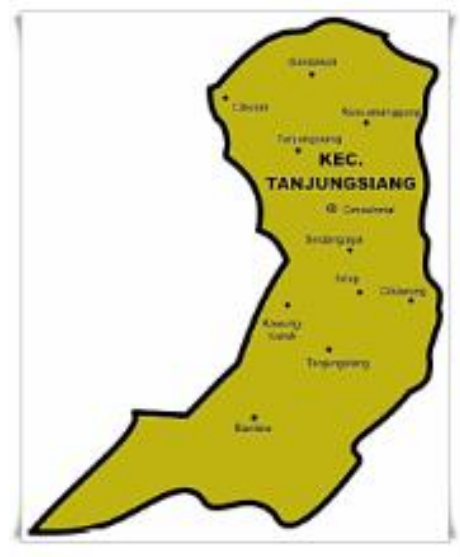

Gambar 1. Letak geografis Desa Rancamanggung Kecamatan Tanjungsiang Kabupaten Subang, Jawa Barat. 
(2003) bahwa studi kasus layak dilakukan bila (a) fokus penelitian adalah untuk menelusur jawaban terhadap pertanyaan "bagaimana" dan "mengapa"; (b) manipulasi terhadap perilaku obyek studi tidak mungkin dilakukan dan (c) perlu peliputan berbagai hal relevan dengan fenomena yang dikaji. Melalui studi kasus, terbuka peluang untuk melakukan eksplorasi fenomena lapangan, yang kemudian dapat diarahkan untuk membangun teori, mengevaluasi program atau pun merancang suatu intervensi (Baxter dan Jack, 2008).

Teknik pengumpulan data yang digunakan adalah wawancara terstruktur dengan menggunakan instrumen berupa daftar pertanyaan. Observasi langsung dilakukan khususnya terhadap kegiatan budidaya ubi kayu yang merupakan sumber mata pencaharian pokok petani Desa Rancamanggung Kecamatan Tanjungsiang. Sampel yang dipilih adalah petani yang mengelola lahan dengan luas maksimal $2000 \mathrm{~m}^{2}$ dan telah berusahatani singkong setidaknya selama 10 tahun. Data dan informasi yang diperoleh dianalisis secara deskriptif agar fenomena lapangan dapat digambarkan secara utuh.

Alasan utama dipilihnya petani yang mengelola lahan relatif sempit adalah karena petani kecil merupakan entitas yang rentan terhadap tekanan, baik ekonomi, maupun lingkungan (Lasco dkk., 2014). Oleh karena itu, upaya untuk memperoleh hasil maksimal dari keterbatasan luasan lahan pertanian biasanya ditunjukkan melalui pemanfataan sumber daya yang cenderung menciptakan tekanan terhadap lingkungan (Mulyadi, 2011). Diasumsikan bahwa untuk memperoleh hasil dari pengelolaan lingkungan yang diharapkan, akan ada upaya untuk beradaptasi terhadap kondisi ekosistem pertanian yang dikelola (Vignola dkk., 2015). Oleh karena itu pengamatan ditujukan pada pola budidaya komoditas yang diterapkan dan memperoleh data serta informasi relevan sehingga terwujud suatu interaksi petani dengan lingkungannya yang tidak eksploitatif. Berdasarkan fenomena tersebut, digunakan sudut pandang ekologi dimana suatu unsur tidak berdiri sendiri akan tetapi terhubung melalui ikatan interaksi di dalam suatu sistem (Berkes dan Folke, 1991; Levin, 1998; Marten, 2008). Penekanan dalam pembahasan diarahkan pada prinsip interaksi antara manusia dan lingkungannya yang kemungkinan telah melalui proses koadaptasi sebagai sebuah konsekuensi dari perubahan-perubahan yang terjadi di berbagai komponen ekosistem (Walker, 2004)

\section{HASIL DAN PEMBAHASAN}

\section{Gambaran Umum Desa Rancamanggung}

Desa Rancamanggung di Kecamatan

Tanjungsiang Kabupaten Subang di Jawa Barat, terletak di areal bertopografi pegunungan dengan ketinggian $700 \mathrm{~m}$ dpl seluas 551,605 ha. Jumlah penduduk yang berada di desa tersebut adalah 2.846 orang, 1494 di antaranya berumur produktif. Sebagian besar penduduk usia produktif, yakni $74,5 \%$ bekerja di sektor pertanian. 825 orang diantaranya bekerja sebagai petani pemilik lahan dan 288 orang bekerja sebagai buruh tani (Anonim, 2013).

Selain bertanam padi di sawah, petani umumnya memiliki lahan kebun yang ditanami ubi kayu sebagai tanaman pokok sumber pendapatan keluarga. Ubi kayu yang dihasilkan dari agroekosistem wilayah ini dikenal bertekstur bagus dan bercita-rasa enak sehingga memiliki harga jual yang relatif tinggi. Dikenal dengan nama "sampeu mangu", ubi kayu tersebut adalah varietas Adira - II yang ditanam secara turun-menurun.. Kalau pun ada varietas lain yang ditanam di kebun petani, jumlahnya tidak signifikan dan umumnya hanya untuk dikonsumsi sendiri.

Ubi kayu yang dihasilkan dari kebun petani, sebagian besar dipasarkan ke luar wilayah kabupaten. Pasar besar Caringin di Kotamadya Bandung merupakan salah satu penampung potensial. Hasil bumi yang dimanfaatkan oleh penduduk sekitar desa, dimanfaatkan oleh usaha kecil pengolah ubi kayu seperti pengrajin pembuat keripik singkong, gitrek, opak. Ubi kayu lokal yang berdiameter kecil sekitar 3-5 cm, digunakan oleh pabrik tapioka lokal. Dengan kata lain, pemanfaatan ubi kayu hasil lahan pertanian di Desa Rancamanggung cukup optimal. Semuanya dapat diserap oleh pasar. Kalau pun ada yang tersisa, adalah untuk penganan keluarga sendiri. Hal yang berkembang dari waktu ke waktu adalah luasan lahan, produksi, diikuti oleh jumlah usaha kecil pengolah singkong. Fakta ini mengindikasikan bahwa keberadaan ubi kayu di lingkungan sendiri mampu menjadi pemicu kreativitas masyarakat lokal dalam mendayagunakannnya sebagai bahan baku bagi kegiatan usaha rakyat, yang potensial untuk dijadikan aset bagi pembangunan desa.

\section{Pola Kelola Ekosistem Pertanian Berdasarkan Ruang dan Waktu}

Selama tiga dekade, petani membudidayakan ubi kayu karena permintaan pasar yang tinggi. Baik pasar lokal, maupun dari luar daerah. Untuk memenuhi permintaan pasar tersebut, petani melakukan pengelolaan lahan pertanian mengikuti dinamika perubahan lingkungan baik iklim, kondisi tanah, serta potensi ekosistem sekitar. Perubahan musim yang membuat lingkungan mikro agroekosistem berubah pun telah dikenal dengan baik oleh para petani, sehingga dapat digambarkan siklus pola penanaman ubi kayu dalam setahun 
secara umum adalah pada Tabel 1. Hanya di bulanbulan tanpa air saja (usum katiga: musim kemarau), petani mengatur diri agar tidak melakukan penanaman bibit ubi kayu.

Menurut para petani, bulan Oktober adalah waktu tanam yang baik. Hal ini karena ketersediaan air mencukupi dan temperatur lingkungan sesuai dengan kebutuhan. Bila hujan, maka penyiapan lahan dapat dilakukan secara lebih mudah, karena tanah menjadi basah dan mudah digemburkan. Kerja penyiapan lahan sepenuhnya dilakukan secara manual menggunakan cangkul. Dalam siklus tanam ubi kayu di Rancamanggung tidak ada sentuhan mekanisasi. Selain karena membutuhkan biaya besar, tidak digunakannya sistem mekanisasi adalah karena topografi lahan yang memiliki kemiringan 40 - 59\%, sehingga sulit mengoperasikan mesin pertanian dalam pengolahan tanah.

Hampir semua petani memberikan waktu untuk lahan beristirahat selama kurang lebih 1 bulan sesudah panen (Tabel 2). Lahan sama sekali tidak ditanami apapun, dengan alasan "siga urang, taneuh oge kedah istirahat, teu tiasa di dur" (seperti hal nya manusia, tanah juga membutuhkan istirahat, tidak bisa terus-terusan dieksploitasi).

Petani membiarkan lahan tidak ditanami selama waktu tertentu untuk "memulihkan diri" agar ketika pada waktunya harus ditanami, tanah sudah siap untuk dikelola lagi.Lamanya lahan beristirahat sangat tergantung pada keinginan petani dan juga ketersediaan air di dalam tanah. Tingkat kelembaban tanah yang menjadi ukuran, tidak dapat dikuantifikasi, namun petani telah mempunyai referensi yang diperoleh dari pengalaman panjang membudidayakan ubi kayu. Biasanya bila air di tanah masih mencukupi, petani hanya akan mengistirahatkan lahan selama 1-2 minggu untuk kemudian langsung dicangkul kasar. Secara biologi, tampaknya "air tanah mencukupi" yang dimaksud adalah air tanah dalam kondisi kapasitas lapang. Kondisi ini memberikan ruang cukup untuk pertumbuhan tunas dan akar menembus tanah (Howeler, 2014). Dengan kata lain, kondisi tanah

Tabel 1. Waktu tanam ubi kayu pada tahun 2013

\begin{tabular}{|c|c|c|c|c|c|c|c|c|c|c|c|c|}
\hline & Jan & Feb & Mar & Apr & Mei & Juni & Juli & Ags & Sep & Okt & Nop & Des \\
\hline Penanaman & $\sqrt{ }$ & $\sqrt{ }$ & $\sqrt{ }$ & $\sqrt{ }$ & $\sqrt{ }$ & $\sqrt{ }$ & & & & $\sqrt{ }$ & $\sqrt{ }$ & $\sqrt{ }$ \\
\hline
\end{tabular}

Keterangan : Usum katiga pada bulan Juli-September, lahan diistirahatkan.

Tabel 2. Perilaku ekologis petani kecil dalam membudidayakan ubi kayu

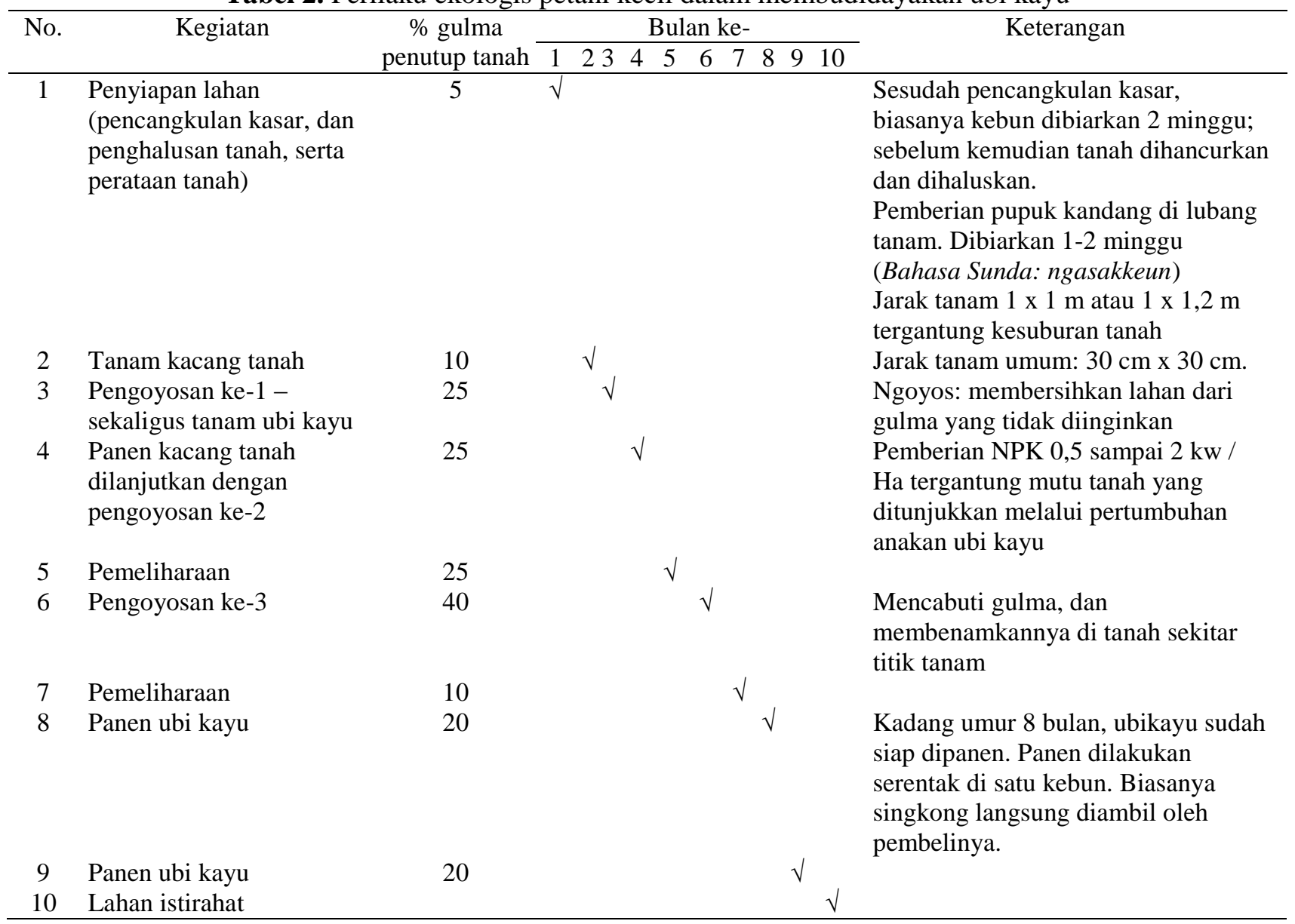

Sumber : Data primer, (2013). 
yang kondusif untuk berlangsungnya proses pertumbuhan tunas dikenali dengan baik oleh petani.

Melalui pola tersebut, produktivitas lahan mencapai rata-rata 207,9 kuintal ubi kayu per hektar, atau di bawah rata-rata produksi ubi kayu Indonesia pada tahun 2014 yakni 229,91 kuintal per hektar (Anonim, 2014). Tingkat produktivitas itu dicapai melalui penerapan pola kelola ekosistem pertanian yang mengombinasikan karakter biologi tanaman ubi kayu dengan tanaman sela kacang tanah atau jahe, kencur, jagung manis.

Kacang tanah merupakan tanaman sela pilihan utama petani ubi kayu. Petani lebih menyukai kacang tanah karena pemeliharaannya yang lebih mudah dan kanopi tanaman ketika sudah umur panen - tidak mengganggu tanaman ubi kayu yang sudah berumur 3 bulan. Tumpangsari dengan tanaman kacang tanah tidak akan membuat kebun menjadi hieum (Bahasa Indonesia : teduh ternaungi oleh kanopi tanaman), kondisi yang dihindari ketika memelihara kebun ubi kayu. Naungan yang banyak akan mengakibatkan meningkatnya populasi hama kumbang uret atau kuuk (Famili : Exopolishipoleuca) yang menyukai kelembaban tinggi.

Kacang tanah ditanam di awal musim tanam di hamparan lahan ubi kayu. Selama 100 hari berada di kebun ubi kayu, tanaman kacang tanah tersebut tidak akan mengganggu perkembangan tanaman pokok, justru membantu menyebarkan $\mathrm{N}$ yang terikat oleh Rhizobium di akar kacang tanah (Howeler, 2014). Struktur morfologis perakaran kacang tanah pun membantu menggemburkan tanah dimana tanaman tersebut berada sehingga ubi kayu yang sedang ada di periode pertumbuhan akan dapat memanfaatkan situasi mikroklimat yang dibutuhkan.

Dengan kata lain kombinasi ubi kayu dengan kacang tanah memenuhi 2 tujuan yakni memperoleh penghasilan tambahan yang diperlukan untuk membiayai pemeliharaan ubi kayu sampai panen, dan untuk mendapatkan tambahan nutrisi dan perbaikan mutu tanah yang disiapkan untuk pertumbuhan tanaman ubi kayu. Tumpang sari biasanya diterapkan sebagai strategi untuk memenuhi peran ekonomi dan ekologi dari agroekosistem (Setiawan, 2009), demikian pula yang ditemukan di komunitas petani kecil pembudidaya ubi kayu Desa Rancamanggung Kabupaten Subang tersebut.

Uraian di atas menggambarkan perilaku petani ubikayu di Desa Rancamanggung Subang dalam mengelola lahan pertaniannya merupakan upaya penyesuaian terhadap kondisi lingkungan yang dinamis. Petani yang menunjukkan upaya adaptasi terhadap dinamika lingkungan melalui berbagai strategi penanganan sumber daya alam termasuk mengatur waktu tanam ditunjukkan pula oleh petani di Adamawa, Nigeria terhadap perubahan iklim yang membutuhkan berbagai penyikapan (Adebayo dkk., 2012). Mengacu pada parameter langkah pengelolaan pertanian berlereng ramah lingkungan seperti dikemukakan oleh Sutrisno dan Heryani (2013), dapat dikemukakan bahwa komunitas petani ubi kayu di Desa Rancamanggung telah menerapkan strategi konservasi tanah dan air. Keterampilan dalam mengelola lahan pertaniannya berjalan sekitar tiga dekade dan menjadi kearifan yang dimiliki tidak saja oleh perorangan akan tetapi komunitas, serta memiliki peluang penerapannya secara berkelanjutan.

Pemikiran untuk selalu dapat memperoleh hasil terbaik dari lahan yang ditangani dalam kurun waktu yang panjang, membuahkan strategi pengelolaan ekosistem pertanian yang sekaligus mampu mempertahankan kekhasan wilayah sebagai produsen ubi kayu berkualitas, khususnya varietas "mangu". Bila petani di Kabupaten Soppeng mengelola lahan pertaniannya dengan pengaruh kearifan lokal sehingga mereka mampu menunjukkan perilaku berwawawasan lingkungan (Mulyadi, 2011), petani ubi kayu di Desa Rancamanggung menunjukkan perilaku pemeliharaan lingkungan pertaniannya dengan motivasi mempertahankan sumber penghasilan keluarga secara turun temurun. Dari penjelasan tersebut, dapat disimpulkan bahwa petani ubi kayu di Rancamanggung adalah komunitas yang telah beradaptasi terhadap ekosistem.

\section{Interaksi Agroekosistem dalam Penerapan Inovasi Budidaya Ubi kayu}

Lahan pertanian merupakan aset pokok penunjang kehidupan petani yang dikelola agar mampu memberikan manfaat berkelanjutan. Hal itu merupakan pola pikir umum yang dimiliki oleh petani dalam mempertahankan kehidupannya dari berbagai tekanan yang harus dihadapi (Beckford, 2009) yang juga menjadi acuan pikir petani ubi kayu Desa Rancamanggung. Pengalaman bertahun-tahun mengelola lahan pertanian inilah yang kemudian menjadi suatu kearifan khas tersendiri yang terkadang tidak terapresiasi. Pada kenyataannya petani dapat menghasilkan inovasi yang terbukti mampu menopang kehidupannya. Apresiasi terhadap fenomena ini menjadi penting mengingat bahwa di dalam progress perkembangan ekonomi, peran dan posisi petani - khususnya petani kecil -di dalam ekosistem pertanian seringkali diabaikan (Beckford, 2009; Soetjipto, 2008).

Petani ubi kayu Desa Rancamanggung paham bahwa tingkat produktivitas lahan akan sangat tergantung pada mutu tanah kebun mereka. Dengan 
memperhatikan pertumbuhan tanaman ubi kayu, mereka akan mengambil keputusan jenis dan jumlah input terhadap tanah yang dibutuhkan. Itu pula yang menyebabkan tidak ada jawaban akurat terhadap pertanyaan jumlah input saprodi yang diaplikasikan pada lahan. Tergantung pada kondisi lahan saat penanaman dan di masa pertumbuhan ubi kayu, dosis pemberian pupuk berkisar antara $50-200$ $\mathrm{kg} / \mathrm{ha}$. Kisaran tersebut mengindikasikan ketajaman daya analisis petani terhadap lingkungan nya dengan keyakinan bahwa input pupuk kimia hanya digunakan ketika benar-benar dibutuhkan. Indikator yang menjadi patokan mereka adalah kinerja pertumbuhan tanaman ubi kayu di bulan pertama. Warna daun, jumlah daun, dan kecepatan tumbuh di masa 30 hari sesudah tanam akan menentukan tindakan lanjut terhadap tanah pertaniannya.

Di periode 10 tahun terakhir, ketika peternakan ayam semakin marak di lingkungan sekitar, maka terwujudlah interaksi antar sistem (Gambar 2). Dari peternakan ayam diperoleh pupuk kandang yang dimanfaatkan, baik untuk perbaikan tanah di lahan sawah terutama di ladang padi gogo maupun untuk kebun singkong. Biasanya pada waktu proses penyiapan lahan, dibutuhkan pupuk kandang yang jumlahnya sekitar 10 ton / Ha. Kebutuhan terhadap kompos ini terpenuhi dengan baik sejak maraknya peternakan ayam di beberapa desa di Kecamatan Tanjungsiang, termasuk di Rancamanggung dan desa yang berdekatan.

Kompos dari kotoran ayam pada akhirnya menjadi pendukung penting terhadap keberlanjutan dari kemampuan lahan kebun menopang kegiatan budidaya ubi kayu. Sebelum marak dengan peternakan ayam, masyarakat Desa Rancamanggung mengenal pemanfaatan kotoran kambing dan sapi sebagai kompos yang dibutuhkan untuk memperbaiki mutu tanah pertanian mereka. Mereka juga telah memahami dengan baik bagaimana membuat kompos yang siap untuk digunakan, dan sangat menyadari bahwa mutu tanah pertanian mereka akan terjaga bilamana aplikasi kompos dilakukan secara teratur. Berdasarkan keterangan petani, waktu aplikasi kompos adalah ketika penyiapan lahan, dengan harapan tanaman muda dapat memperoleh nutrisi cukup untuk pertumbuhannya karena telah dibantu oleh penggemburan tanah sehingga memudahkan akar untuk tumbuh menembus tanah. Pembuatan kompos dari kotoran ayam ini merupakan ide yang prospektif untuk memperbesar kontribusi peternakan ayam terhadap keluarga petani. Pendayagunaan kotoran ayam memang diperlukan untuk meningkatkan kontribusinya pada pendapatan keluarga (Mukhtar, 2013), di sisi lain membantu petani yang memerlukan asupan nutrisi tambahan bagi tanah

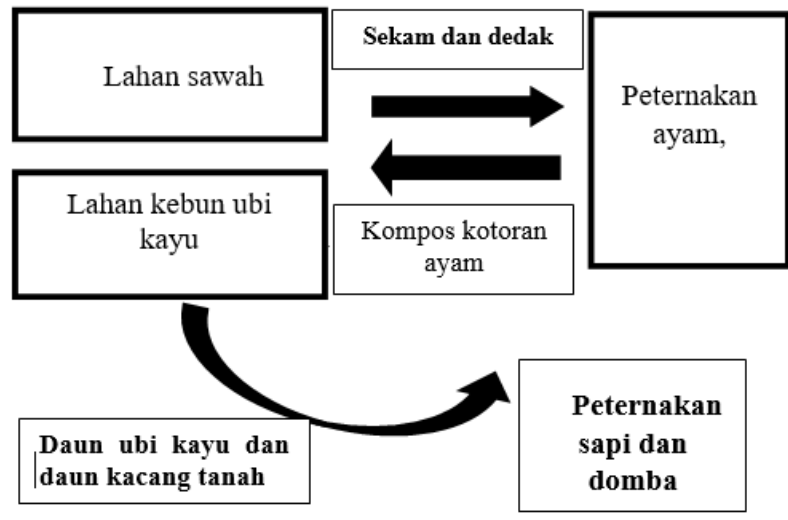

Gambar 2. Interaksi agroekosistem di Rancamanggung.

pertaniannya. Simbiosis mutualisma inilah yang terwujud di ekosistem pertanian ubi kayu Desa Rancamanggung.

\section{Koadaptasi : Fenomena Petani Ubi Kayu dan Lingkungan Pertaniannya}

Koadaptasi adalah sebuah fenomena yang dapat terjadi karena proses adaptasi di suatu wilayah geografi tertentu atau terhadap suatu situasi yang dihadapi dalam periode waktu tertentu (Marten, 2008). Keberhasilan petani kecil pembudidaya ubi kayu di Rancamanggung dalam mempertahankan mutu lingkungan pertaniannya dalam periode waktu tiga dekade merupakan wujud dari sebuah proses koadaptasi. Hal itu membuktikan bahwa mereka adalah komunitas yang mampu beradaptasi bersama dengan perubahan ekosistem. Dapat disimpulkan bahwa terbukanya peluang pasar ubi kayu "mangu" telah mengubah rona lingkungan pertanian Desa Rancamanggung secara signifikan. Semula, ubi kayu merupakan tanaman sela, berubah menjadi tanaman pokok di hamparan lahan pertanian. Perubahan ini membutuhkan penyesuaian perilaku ekologis terhadap lingkungan biotis maupun abiotis. Penyesuaian juga ditunjukkan dengan kecermatan petani kecil dalam memanfaatkan sumber daya lokal dan berinteraksi dengan agroekosistem setempat (Gambar 2).

Hubungan resiprokal antar sistem tersebut memberikan manfaat jangka panjang berupa terjaganya mutu lingkungan yang diindikasikan dari produktivitas lahan dan mutu produk ubi kayu yang dihasilkan. Upaya untuk mempertahankan mutu lingkungan dengan menerapkan usaha tani konservasi adalah juga adalah strategi adaptasi yang diterapkan oleh komunitas petani di hulu DAS Jeneberang Sulawesi Selatan (Nuraeni dkk. 2013). Upaya mengadaptasi diri dengan kondisi lingkungan adalah perilaku ekologis yang terbangun dari proses interaksi di periode waktu yang tidak pendek dimotivasi oleh harapan mempertahankan 
produktivitas lahan pertanian dalam waktu yang panjang (Santoso, 2006; Derbile dan Laube, 2014).

Fenomena di Rancamanggung membuktikan bahwa petani kecil mengelola sumber daya alam tanpa harus dipengaruhi oleh sifat konsumtif materialistik yang dapat menimbulkan tindak eksplotatif terhadap ekosistem (Armawi, 2013). Bahkan sebagai komunitas petani kecil, ternyata mereka tidak berhenti berinovasi. Inovasi ekologi yang dihasilkan bersama berjalannya waktu mengindikasikan bahwa sebagai komunitas petani kecil, proses demand-driven, diupayakan untuk tetap dapat dipenuhi tanpa harus mengorbankan keberlanjutan dukungan ekosistem.

Konflik sosio-ekologis pada eksploitasi sumber daya alam yang didorong oleh pandangan individualistik-materialistik yang sebetulnya potensial terjadi (Armawi, 2013), pada kasus budi daya ubi kayu di wilayah studi, tidak terjadi. Fenomena tersebut merupakan indikasi kapasitas sosio-ekologis yang baik bagi pemenuhan kebutuhan sosio-ekonomi petani yang memiliki berbagai keterbatasan. Kapasitas sosio-ekologis yang merupakan menjadi modal penting dalam mempertahankan diri dari tekanan faktor external, baik dalam benntuk tekanan ekonomi maupun sosial (Walker dkk. 2004). Gambaran tersebut membuktikan bahwa peran petani kecil dalam skema strategis pembangunan desa tidak dapat diabaikan. Seringkali petani hanya diletak-dudukan sebagai obyek dan bukan subyek penting yang seharusnya memperoleh manfaat dari berbagai tindak strategis pembangunan desa, atau terjadi bias perlakuan terhadap petani yang memiliki lahan luas dengan status sosial - ekonomi tinggi (Altieri, 2002).

Upaya tata kelola sumber daya lokal seperti ditunjukkan oleh petani kecil pembudidaya ubi kayu di Rancamanggung Kabupaten Subang, layak untuk dikaji lebih dalam -khususnya dari sisi sosioekologis - sehingga dapat dijadikan acuan secara utuh bagi perancang strategi pengembangan ekosistem pertanian berbasis komoditas ubi kayu. Suatu langkah antisipatif penting bagi Indonesia yang mencanangkan kebijakan kedaulatan pangan dalam skema pikir pembangunan inklusif

\section{KESIMPULAN}

Berdasarkan studi kasus yang dilakukan di Desa Rancamanggung Kecamatan Tanjungsiang Kabupaten Subang, petani kecil yang mengelola lahan pertanian seluas $500-2000 \mathrm{~m}^{2}$ beradaptasi dengan terus-menerus melakukan inovasi budidaya di agroekosistem ubi kayu. Inovasi yang diterapkan untuk memenuhi fungsi ekonomi dan fungsi sosial dari ubi kayu, secara sadar juga dilakukan untuk menjaga kemampuan lahan pertanian menunjang kegiatan budidaya ubi kayu secara berkelanjutan.

Inovasi terus-menerus tersebut merupakan wujud koadaptasi petani dengan lingkungan pertaniannya yang dilakukan berdasarkan kepercayaan bahwa terdapat batas kemampuan lingkungan dalam mendukung kinerja budidaya tanaman. Pengertian tersebut mendasari keputusan untuk mengelola agroekosistem ubi kayu dengan memanfaatkan berbagai sumber daya lokal, baik produk samping kegiatan peternakan, maupun gulma di hamparan lahan ubikayu.

\section{UCAPAN TERIMAKASIH}

Tanpa dukungan dari Pusat Pengembangan Teknologi Tepat Guna LIPI dan Balai Penyuluh Pertanian Kecamatan Tanjungsiang, pengenalan terhadap masyarakat Tanjungsiang tidak akan dapat dilakukan. Terimakasih secara khusus disampaikan pada penyuluh pertanian lapangan, M. Subarnas dan Edeng Sopia yang membantu melancarkan pelaksanaan pengamatan lapangan; dan keluarga Pak Aman - Bu Maryati di Sindang Laya Tanjungsiang yang membuka mata kami terhadap potensi sosial-ekonomi masyarakat sekitar.

\section{DAFTAR PUSTAKA}

Adebayo, A.A., Onu, J.I., Adebayo, E.F., dan Anyanwu, S.O., 2012. Farmers' Awareness, Vulnerability and Adaptation to Climate Change in Adamawa State, Nigeria. British Journal of Arts and Social Sciences, 9(2):104115.

Altieri, M., 2002. Agroecology: The Science of Natural Resource Management for Poor Farmers in Marginal Environment. Agriculture, Ecosystems \& Environment. 1971:1-24

Anonim, 2013. Kecamatan Tanjungsiang dalam Angka. Kecamatan Tanjungsiang Kabupaten Subang, Subang.

Anonim, 2014. Luas Panen- ProduktivitasProduksi Tanaman Ubi Kayu Seluruh Provinsi. Kementerian Pertanian Republik Indonesia. $\quad \mathrm{http} / / / \mathrm{www}$. pertanian.go.id/ ap_pages/ mod/datalimatahun (Diakses tanggal 18 Desember 2015).

Armawi, A., 2013. Kajian Filosofis terhadap Pemikiran Human-Ekologi dalam Pemanfaatan Sumberdaya Alam. Jurnal Manusia dan Lingkungan, 20(1):57-67.

Baxter, P. dan Jack, S., 2008. Qualitatitive Case Study Methodology : Study Design and Implementation for Novice Researchers. The Qualitative Report, 13 (4): 544-559. 
Beckford, C.L., 2009. Sustainable Agriculture and Innovation Adoption in a Tropical SmallScale Food Production System: The Case of Yam Minisetts in Jamaica. Sustainability, l(1):81-96.

Berkes, F. dan Folke, C., 1993. A Systems Perspective on the Interrelationships between Natural, Human-Made and Cultural Capital. Ecological Economics, 5(1):1-8.

Derbile, E.K., dan Laube, W., 2014. Local Knowledge Flows for Reducing Vulnerability of Rain-fed Agriculture to Environmental Change: Patterns and Drivers of Flow in North-Eastern Ghana. Information and Knowledge Management. 4(7):24-39.

Fermont, A.M., Babirye, A., Obiero, H.M., Abele, S., dan Giller, K.E., 2010. False Beliefs on The Socio-Economic Drivers of Cassava Cropping. Journal of Agronomy Sustainable Development, 30:433-444.

Howeler, R., 2014. Sustainable Soil and Crop Management of Cassava in Asia. Centro International de Agricultura Tropical. Cali.

Lasco, R.D., Delfino, R.J.P., Catacutan, D.C., Simelton, E.S. dan Wilson, D.M., 2014. Climate Risk Adaptation by Smallholder Farmers: the Roles of Trees and Agroforestry. Current Opinionn in Environmental Sustainability, 6:83-88.

Levin, S.A., 1998. Ecosystems and the Biosphere as Complex Adaptive Systems. Ecosystems, 1:43-436.

Marten, G.G., 2008. Human Ecology - Basic Concepts for Sustainable Development. Third Edition. Earthscan Publication, London.

Mukhtar, 2013. Pengembangan Usahatani Ternak Ayam Buras oleh Petani Miskin di Teluk Kulisusu Kabupaten Buton Utara Provinsi Sulawesi Tenggara. Jurnal Manusia dan Lingkungan, 20(2):164-172.

Mulyadi, 2011. Pengaruh Kearifan Lokal, Locus of Control, dan Motivasi terhadap Perilaku Berwawasan Lingkungan Petani dalam Mengelola Lahan Pertanian di Kabupaten Soppeng. Jurnal Manusia dan Lingkungan, 18(1):60-67.

Mwango, S.B., Msanya, B.M., Mtakwa, P.W., Kimaro, D.N., Deckers, J., Poesen, J., Lilanga, S., dan Sanga, S., 2014. Soil Loss Due to Crop
Harvesting in Usambara Mountains, Tanzania: The Case of Carrot, Onion and Potato. International Journal of Plant \& Soil Science, 4(1):18-28.

Nuraeni, Sugiyanto, dan Zaena, 2013. Usahatani Konservasi di Hulu DAS Jeneberang (Studi Kasus Petani Sayuran di Hulu DAS Jeneberang Sulawesi Selatan). Jurnal Manusia dan Lingkungan, 20(2):173-183.

Ruysschaert, G., Poesen, J., Verstraeten, G., dan Govers, G., 2007. Soil Loss Due to Harvesting of Various Crop Types in Contrasting AgroEcological Environments. Agriculture, Ecosystem and Environment, 120:153-165.

Santoso, I., 2006. Eksistensi Kearifan Lokal pada Petani Tepian Hutan dalam Memelihara Kelestarian Ekosistem Sumber Daya Hutan. Jurnal Wawasan, 11(3):11-16.

Setiawan, E., 2009. Kearifan Lokal Pola Tanam Tumpang Sari di Jawa Timur. Agrovigor, 2(2):79-88.

Soetjipto, 2008. Adaptasi Geografi Masyarakat Petani Madura di Pedukuhan Baran Kelurahan Buring Malang. Jurnal MIPA, 37(1):97-102.

Sutrisno, N., dan Heryani, N., 2013. Teknologi Konservasi Tanah dan Air untuk Mencegah Degradasi Lahan Pertanian Berlereng. Jurnal Litbang Pertanian, 32(3):122-130.

Tongchure S., dan Hoang N., 2013. Cassava Smallholders' Participation in Contract Farming in Nakhon Ratchasrima Province, Thailand. Journal of Social and Development Sciences, 4(7):332-338.

Vignola, R, Harvey, C.A., Bautista-Solis, P., Avelino, J., Rapidel, B., Donatti, C. dan Martinez, R., 2015. Ecosystem-based Adaptation for Smallholder Farmers: Definitions, Opportunities and Constraints. Agriculture, Ecosystems and Environment, 211:126-132.

Walker, B., Holling, C.S., Carpenter, S.R., dan Kinzig, A., 2004. Resilience, Adaptability and Transformability in Social-Ecological Systems. Ecology and Society, 9(2):5.

Yin, R.K., 2003. Case Study Research: Design and Methods. Third Edition. Thousand Oaks, Sage, California. 